\title{
Safety Assessment of Underground Vehicles Passing Over Highly Resilient Straight Tracks in the Presence of a Broken Rail
}

\author{
F. J. Gonzalez, B. Suarez, J. Paulin and I. Fernandez
}

In this paper, vehicle-track interaction for a new slab track design, conceived to reduce noise and vibration levels has been analyzed, assessing the derailment risk for trains running on curved track when encountering a broken rail. Two different types of rail fastening systems with different elasticities have been analysed and compared.

Numerical methods were used in order to simulate the dynamic behaviour of the train-track interaction. Multibody system (MBS) modelling techniques were combined with techniques based on the finite element method (FEM). MBS modelling was used for modelling the vehicle and FEM for simulating the elastic track. The simulation model was validated by comparing simulated results to experimental data obtained in field testing.

During the simulations various safety indices, characteristic of derailment risk, were analysed. The simulations realised at the maximum running velocity of $110 \mathrm{~km} / \mathrm{h}$ showed a similar behaviour for several track types. When reducing the running speed, the safety indices worsened for both cases. Although the worst behaviour was observed for the track with a greater elasticity, in none of the simulations did a derailment occur when running over the broken rail. 


\title{
Safety Assessment of Underground Vehicles Passing Over Highly Resilient Straight Tracks in the Presence of a Broken Rail
}

\author{
F J Gonzalez ${ }^{1}$, B Suarez ${ }^{2 *}$, Paulin $^{2}$ and I Fernandez ${ }^{1}$ \\ ${ }^{1}$ Metro de Madrid S.A., Madrid, Spain \\ ${ }^{2}$ Railway Technologies Research Centre (CITEF), Universidad Politecnica de Madrid, Madrid, Spain \\ * Corresponding author: CITEF, C/ José Gutiérrez Abascal n² 2, ES-28006 Madrid, Spain, email: \\ citef.bsuarez@etsii.upm.es
}

\begin{abstract}
In this paper, vehicle-track interaction for a new slab track design, conceived to reduce noise and vibration levels has been analyzed, assessing the derailment risk for trains running on curved track when encountering a broken rail. Two different types of rail fastening systems with different elasticities have been analysed and compared.

Numerical methods were used in order to simulate the dynamic behaviour of the train-track interaction. Multibody system (MBS) modelling techniques were combined with techniques based on the finite element method (FEM). MBS modelling was used for modelling the vehicle and FEM for simulating the elastic track. The simulation model was validated by comparing simulated results to experimental data obtained in field testing.

During the simulations various safety indices, characteristic of derailment risk, were analysed. The simulations realised at the maximum running velocity of $110 \mathrm{~km} / \mathrm{h}$ showed a similar behaviour for several track types. When reducing the running speed, the safety indices worsened for both cases. Although the worst behaviour was observed for the track with a greater elasticity, in none of the simulations did a derailment occur when running over the broken rail.
\end{abstract}

Keywords: slab track, resilient track, block spacing, vehicle-track interaction, broken rail, rail breakage, simulation, derailment risk, safety, running stability

\section{$1 \quad$ Introduction}

In recent years a lot of research has been conducted in the field of railway vehicle dynamics simulation. $[1,2]$ summarize the state-of-the-art about this topic. In particular, the detailed study of vehicle-track interaction was a focus for many researchers and engineers. Modelling techniques for simulation of track and vehicle-track interaction dynamics can be found in [3-13] Nevertheless, little has been investigated in the field of damaged tracks and broken rails and their influence on the vehicle's riding behaviour and safety, with the exception of the analytical work realised by Eisenmann [14]. Some interesting statistical results can also be found in $[15,16]$. Otherwise, though being a different phenomenon, impact loads at rail joints or turnouts keep some resemblance with the dynamic effect observed when a wheel passes over a broken rail. This phenomenon is treated in [17-21].

This paper presents the results of a research study that dealt with the simulation of vehicle-slab track interaction including discontinuous effects, such as a broken rail, shown in Fig. 1. 


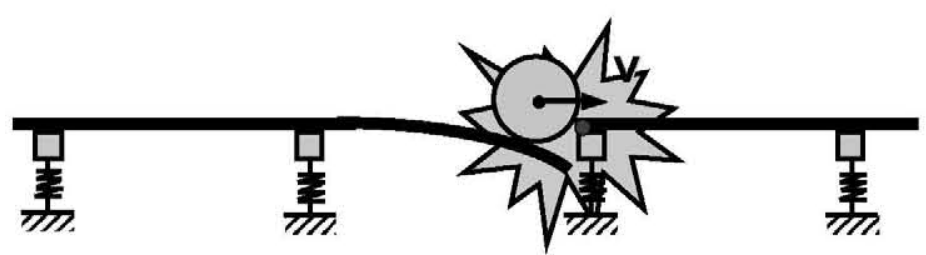

Fig. 1. The problem of a broken rail

The work here presented is the result of a collaboration project realised between the Railway Technology Research Centre, CITEF (Centro de Investigación en Tecnologías Ferroviarias), of the Polytechnic University of Madrid, UPM (Universidad Politécnica de Madrid), and the Engineering Department for Maintainence and R\&D of the Madrid underground operator (Metro de Madrid).

The project was proposed by Metro de Madrid when considering the possibility of installing a new slab track system with a higher elasticity in order to improve the acoustical and vibrational behaviour of the track. Formerly, Metro requested to its usual slab track supplier to modify its track design, in order to reduce noise and vibration levels. This new design resulted in a slab track similar to the one already installed in this railway administration's network, but with quite higher damping and resilience properties. As is well known, an excessive increment in the slab track's elasticity leads to greater vertical displacements, which could affect vehicle and track stability. Some other considerations concerning the behaviour of highly resilient tracks can be found in [22-24].

Railway Administrations have to deal with broken rails to a greater or lesser extent. As an example, Fig. 2 shows the Rail Breakage Index, $R B I$, recorded at Metro de Madrid during the years 1992-2002. The $R B I$ is defined as the number of breakages per track kilometre and year.

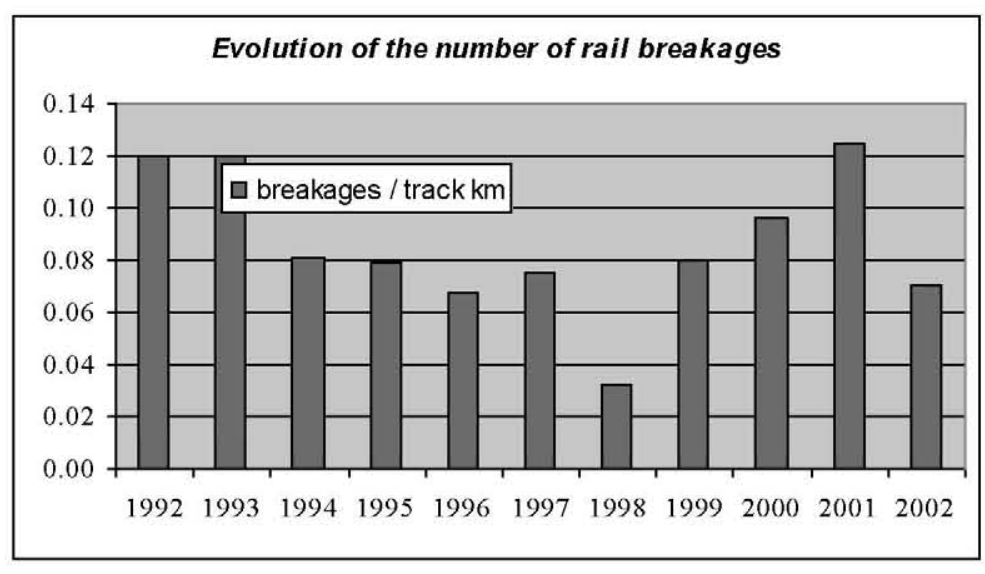

\begin{tabular}{|c|c|c|c|}
\hline Year & $\begin{array}{c}\text { No. } \\
\text { breakages }\end{array}$ & $\begin{array}{c}\text { km } \\
\text { (double } \\
\text { track) }\end{array}$ & $\begin{array}{c}\text { Breakages } \\
\text { per } \\
\text { track km }\end{array}$ \\
\hline 1992 & 28 & 117 & 0.12 \\
\hline 1993 & 28 & 117 & 0.12 \\
\hline 1994 & 19 & 118 & 0.08 \\
\hline 1995 & 20 & 126 & 0.08 \\
\hline 1996 & 17 & 126 & 0.07 \\
\hline 1997 & 19 & 126 & 0.08 \\
\hline 1998 & 9 & 140 & 0.03 \\
\hline 1999 & 28 & 176 & 0.08 \\
\hline 2000 & 34 & 176 & 0.10 \\
\hline 2001 & 44 & 176 & 0.13 \\
\hline 2002 & 27 & 191 & 0.07 \\
\hline
\end{tabular}

Fig. 2. The Rail Breakage Index at Metro de Madrid

It should be noticed that for the calculation of the $R B I$ ("Breakages per track kilometre" in Fig. 2) the column indicating the total track kilometres ("km (double track) in Fig. 2") was multiplied by two, since in Metro de Madrid all installations are of "double track" type. The analysis of the data showed that the majority of rail breakages occur at the rail joints and throughout the winter months.

Regarding all of the above-mentioned concerns, it was decided to perform a preliminary study focussed on comparing the behaviour of two resilient slab track systems in simulation. The results of this study are presented below. The results obtained will be employed in further decision making on whether or not to install superelastic slab track in future infrastructure projects. 


\subsection{Introduction to slab tracks}

The idea of substituting the common ballast track system with slab track first appeared in the 1960 s with high-speed on the rise. In that era, engineers developed the first vehicles designed for $200 \mathrm{~km} / \mathrm{h}$ and more. New types of track systems were developed that fulfilled and maintained the small geometric tolerances that are required when running at high-speed. The new types of track developed usually consist of a concrete slab as the main component of the structure (Fig. 3 and Fig. 4). The rails are fixed to the sleepers or independent blocks that rest on the slab. An elastomer is placed between the sleepers or blocks and the concrete slab in order to substitute the original function of the ballast bed [25-28].

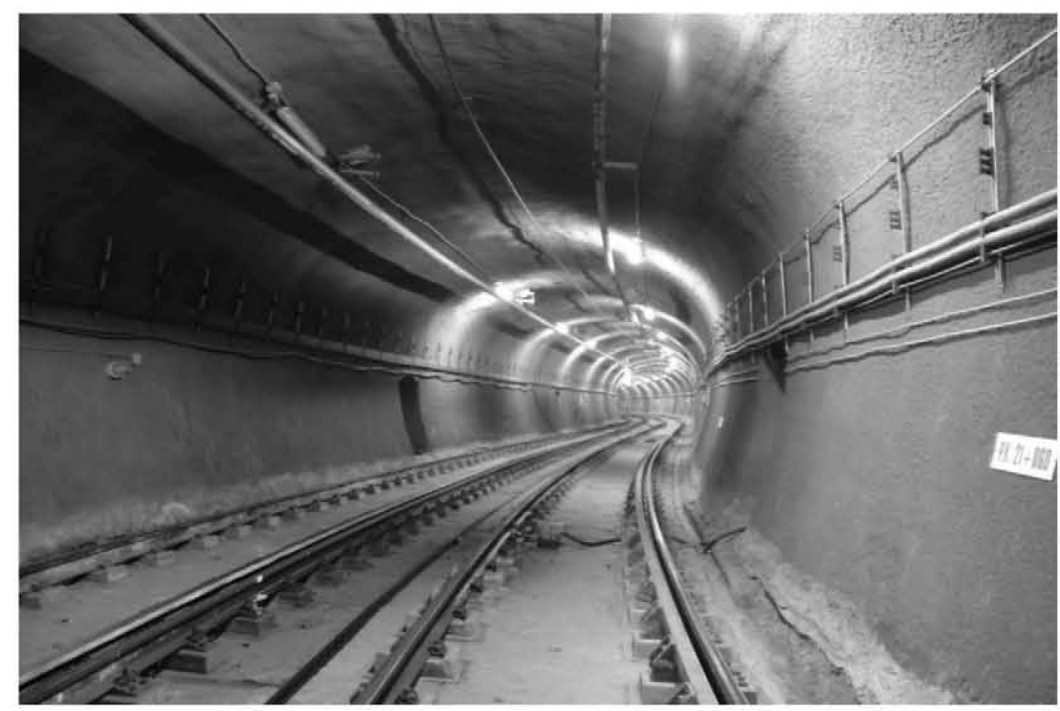

Fig. 3. Slab track installation

Slab tracks maintain their geometric positioning over long periods of time. This is their main advantage, as it reduces the need for maintenance work. Since the possible track defects are fewer, the damage done by the vehicle to the track is also lower, thus guaranteeing longer maintenance intervals. The following list reveals additional advantages of slab track [3, 26-27]:

- Smooth, uniform wheelset riding

- Lower track settlement compared to ballast tracks

- Lower pressures transmitted to the track bed

- Reduced cross section needed in tunnels due to its reduced height

- Easy evacuation of passengers and the possibility to include an access lane for emergency vehicles

- Greater resistance to damage caused by derailment accidents

On the other hand, slab track presents some disadvantages in comparison to standard ballast tracks. The major inconvenience is its greater construction costs, even though they are compensated by lower maintenance costs [29]. To this disadvantage can be added the fact that it is more difficult to repair slab tracks once they are damaged or when faced with a defective installation.

\subsection{The Slab Track System Installed in Metro de Madrid}

The high traffic intensity, characteristic of suburban train operation, makes maintenance work extremely difficult. It has to be realised after the daily operational schedule and is usually limited to $2.5 \mathrm{~h}$ per day $[26,27]$. In addition, the space available for maintenance machinery in tunnels is reduced and makes maintenance work more difficult. Due to all these factors a ballast-free slab track system is especially suitable for the infrastructure maintenance of underground metropolitan railway networks. 
In Metro de Madrid the first slab track system was installed in almost all underground stations from 1975. Even though, until 1987, ballast track with wooden sleepers was still installed in the rest of the underground network [27]. From 1987 on, all new track construction was built in slab, with the exception of the turnouts. It was not until 1995 when the turnouts were also fabricated in slab track.

When, in 1995, a new Metro de Madrid expansion plan was launched, a research project was commissioned in order to determine the best slab track alternatives for their future underground lines. The results of this project led to the conclusion that the most appropriate track system was the Edilon embedded block system [27].

Instead of sleepers this system uses two independent concrete blocks (Fig. 4) [26, 27, 30-33]. These blocks are jointed to their corresponding trays by means of an elastomeric compound, thus forming a prefabricated structure called embedded block. The final slab track is then constructed by pouring concrete underneath the embedded blocks until the concrete level reaches the height of the trays and forms the concrete slab. Finally, the rails are fixed on top of the embedded blocks. The spacing between two adjacent blocks is usually fixed to $1.0 \mathrm{~m}$ for straight tracks. In curved tracks the block spacing may vary from 0.75 to $1.0 \mathrm{~m}$, depending on the curve radius. The rails are clamped to the embedded blocks by means of standard fastening mechanisms. An elastic rail pad is introduced between the rail and the embedded block.

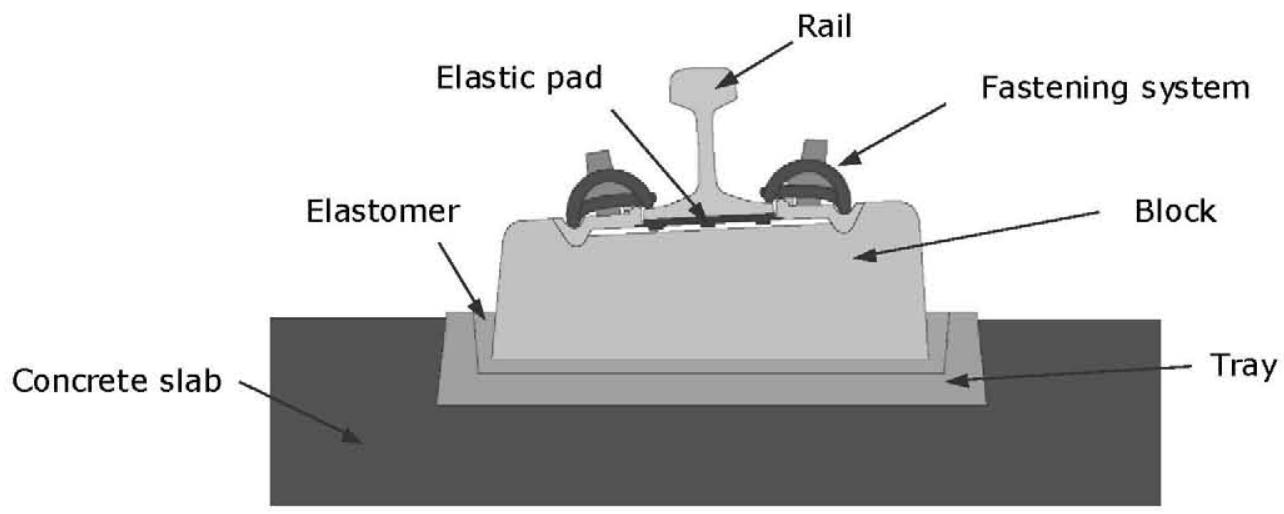

Fig. 4. The embedded block system of the slab track

In the 1995-1999 expansion plan heavier and faster vehicles were acquired. The increase in the axle load (from 12.5 to $15.5 \mathrm{t}$ ) and the higher running velocity (from 70 to $110 \mathrm{~km} / \mathrm{h}$ ), implied an amplification of the transmitted vibration levels. The standard Edilon independent block system (Embedded Block System - Standard Stiffness, EBS-SS) that was initially installed was appropriate for the new operating conditions. Nevertheless, according to Metro de Madrid's development policies, it was decided to install a track system with an even better performance in order to improve passenger comfort and reduce noise and vibration emissions. The behaviour of the new, more elastic system, called EBS-MS (Medium Stiffness), was installed in Metrosur and has given highly satisfactory results. Still, even after a successful installation of the EBS-MS system in Metrosur, Edilon developed another, even more elastic system, called EBS-LS (Low Stiffness) for future projects.

The following stiffness and damping properties have been determined by experiment [30]:

\begin{tabular}{|c|c|c|c|}
\hline Parameter (slab track) & SS System & MS System & LS System \\
\hline Block spacing, $l$ & \multicolumn{3}{|c|}{$1.0 \mathrm{~m}$} \\
\hline Vertical stiffness, $k$ & $60.0 \mathrm{kN} / \mathrm{mm}$ & $15.5 \mathrm{kN} / \mathrm{mm}$ & $7.0 \mathrm{kN} / \mathrm{mm}$ \\
\hline Vertical damping, $d$ & $29.5 \mathrm{kNs} / \mathrm{mm}$ & $4.54 \mathrm{kNs} / \mathrm{mm}$ & $4.1 \mathrm{kNs} / \mathrm{mm}$ \\
\hline
\end{tabular}

Table 1. Elastic properties of the EBS-SS, EBS-MS and EBS-LS systems 
Traditionally, there are two different approaches for studying the dynamics of vehicle-track interaction. On the one hand, there is the multibody system approach which is usually used in studies that deal with the analysis of the vehicle's dynamic behaviour. In these models the track is usually considered to be rigid and the wheel-rail interaction forces are calculated by applying specialised theories, such as the Kalker theory. On the other hand, there is the finite element method approach, habitually employed in studies dealing with the dynamics of the track. In these studies the track is modelled as an elastic system. The vehicle model is usually less complex and does not take into account the tangential wheel-rail contact forces. An extended state-of-the-art review of the dynamic modelling of the track and its interaction with the vehicle can be found in references $[1,2,34,35]$.

In this work both modelling techniques have been integrated. A complex 3-D vehicle model has been combined with an elastic track model (Fig. 5). The wheel-rail contact forces are crucial for studying derailment risk and therefore have to be considered in the modelling. The track's elastic behaviour may not be disregarded either, since a broken rail was to be modelled. The modelling techniques employed allow for extending the research to curved tracks, which is usually not considered in the above-mentioned traditional elastic track models.

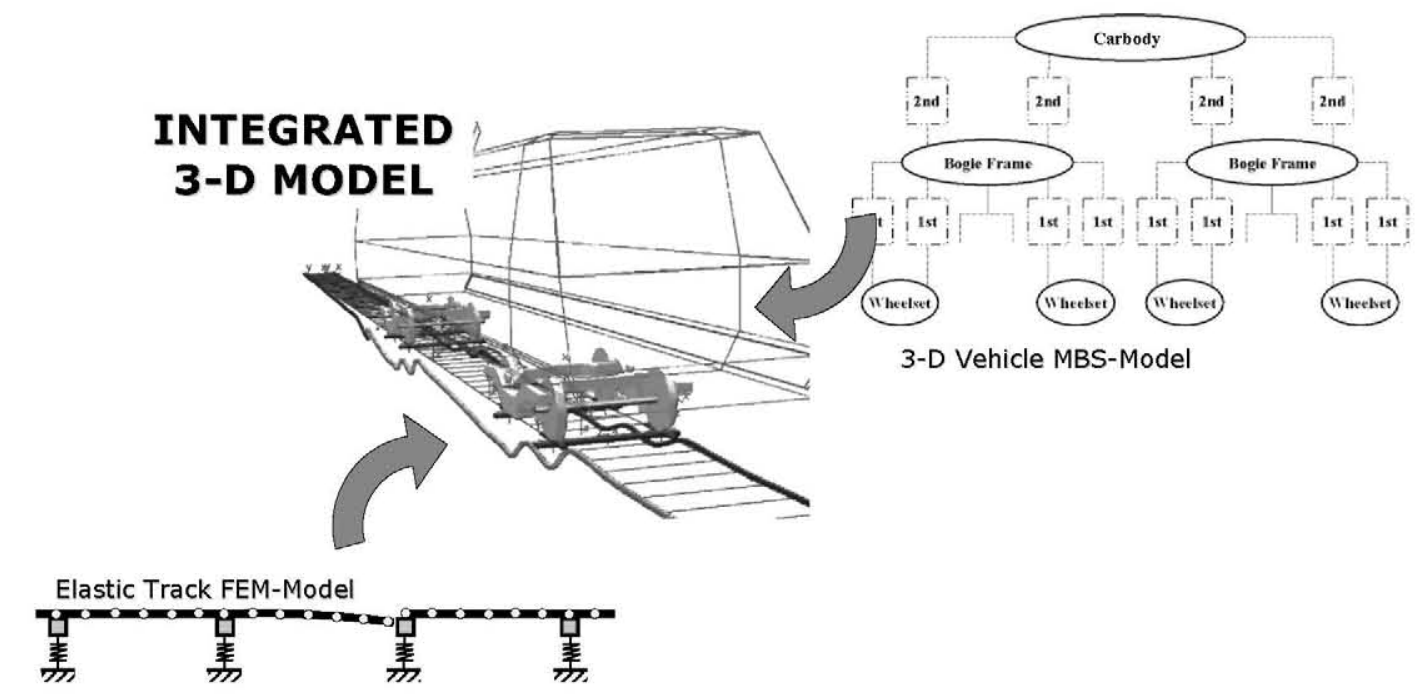

Fig. 5. The integrated modelling technique used

The vehicle was modelled as a multibody mechanism in the SIMPACK simulation tool. The resilient slab track has been incorporated into the MBS program by means of elastic bodies, previously defined in the ANSYS finite element program.

\subsection{Description of the Vehicle Model}

The vehicle chosen for this study was a metropolitan train coach of the 6000 series from Metro de Madrid's rolling stock (Fig. 6). 

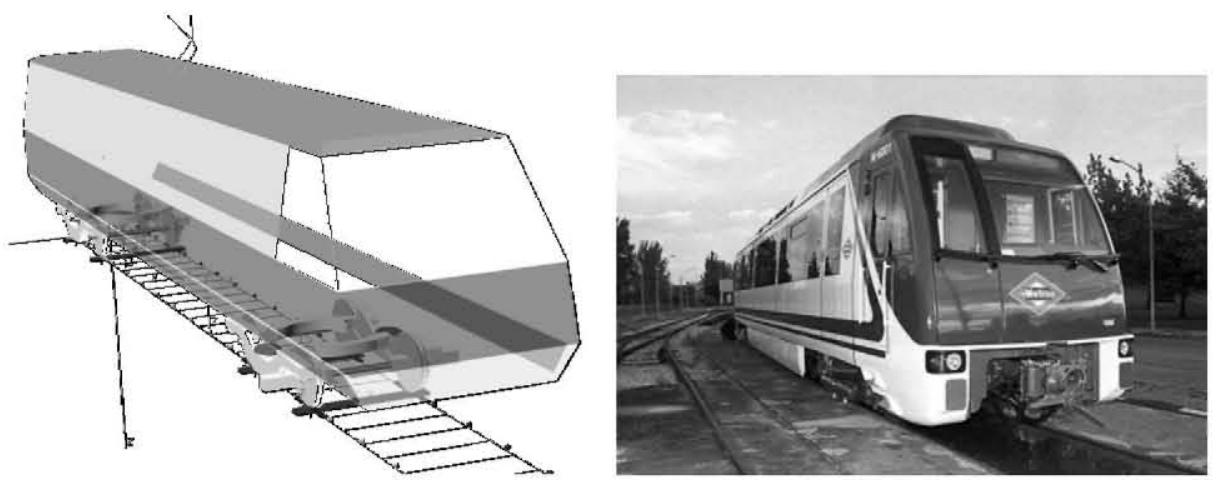

Fig. 6. The final vehicle model

It is a standard metropolitan train that has been modelled by rigid bodies (a carbody, two bogie frames and four wheelsets). Spring and damper elements have been used for the primary and secondary suspensions, as can be seen in Fig. 7. The model has been extensively described in [36].

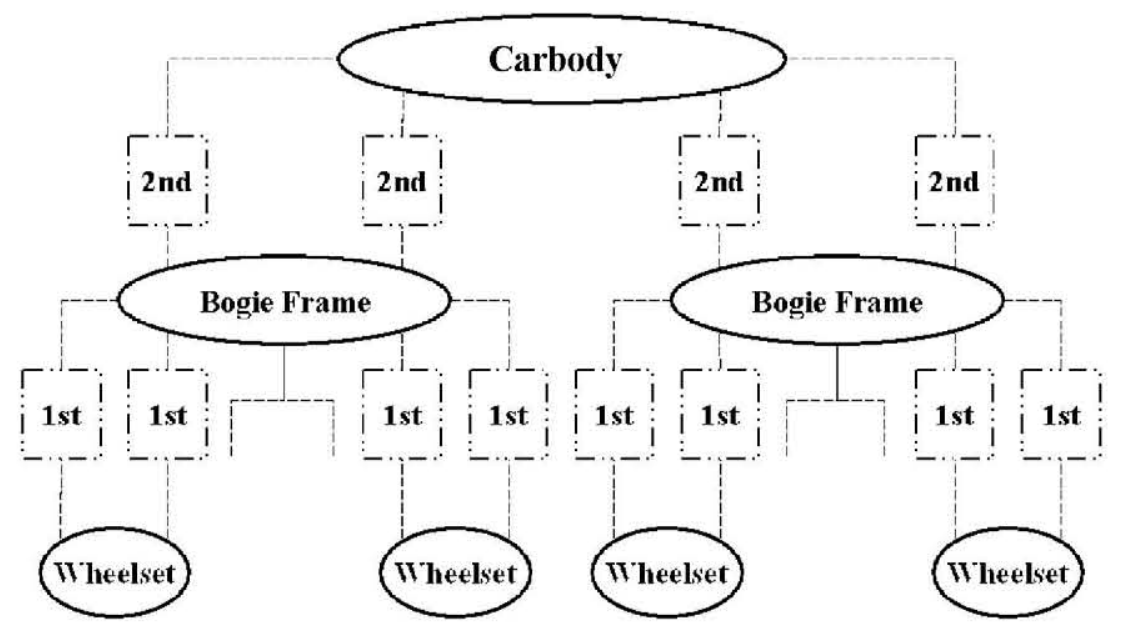

Fig. 7. The final vehicle model - topologic diagram

This representation of the real vehicle through rigid bodies and force elements relates vehicle modelling to MBS dynamics. Railway vehicles have two peculiar characteristics that distinguish them from general multibody system models:

- Forced guidance of the vehicle (enforced by the track)

- Complex wheel-rail contact (great forces acting on a small contact patch)

Therefore, in vehicular dynamics studies, a railway specific multibody system simulation program is required that incorporates and calculates all of these features. As has been mentioned earlier, SIMPACK has been used for MBS-modelling since it provides a special railway module.

\subsection{Description of the Track Model}

The track analysed in the study was Metro de Madrid's modern slab track that has been described above [31]. The equivalent slab track model can be characterised by the following two components:

- $\quad$ Elastic steel rails (UIC 54)

- Embedded blocks (with the characteristics indicated in Table 1)

The stiffness and damping parameters used for describing the track's behaviour, include the elastic properties of the fastening system, the elastic rail pad, the embedded block, and the elastomer located between blocks and trays (Fig. 4). 
The elastic rails were modelled in the ANSYS FEM-program and later introduced in the SIMPACK MBS-program. The discrete embedded blocks are modelled in SIMPACK by means of force elements.

Even though the employed modelling technique allows for the construction of any kind of track model, in this study only straight tracks have been taken into account. Curved tracks and the required superelevation of the track have not yet been considered but are the subject of a current study.

\subsubsection{Modelling in ANSYS}

In the final simulation model, a 48-m-long straight track was set up. The degrees-of-freedom in that model were restricted to bending in the vertical plane only. Three rails were modelled in ANSYS by means of Rayleigh-Timoshenko unidimensional beams, with the node spacing for all rails being $0.1 \mathrm{~m}$ :

- One beam with a total length of $48 \mathrm{~m}$ (corresponding to the left rail)

- Two beams with length of $24 \mathrm{~m}$ each (corresponding to the right rail)

The right rail incorporates the gap that simulates the broken rail, thus two $24 \mathrm{~m}$ rails were used instead of one entire $48 \mathrm{~m}$ one, as can be seen in Fig. 8 .

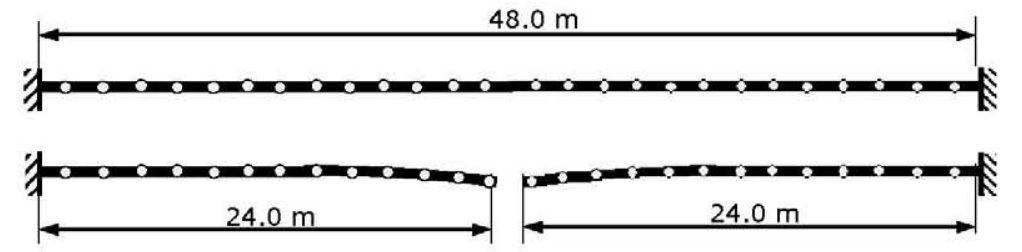

Left side (1 rail):

clamped-clamped beam

Right side (2 rails):

cantilever beams

Fig. 8. The boundary conditions (clamped-clamped and cantilever beam)

At the rail-ends clamped-clamped boundary conditions were applied in order to allow a smooth entry of the vehicle into the elastic track model. A sufficiently long model length was chosen so that the disturbance introduced by the boundary conditions would not affect the central part of the model where the gap in the broken rail was located. After applying the mentioned boundary conditions, the mass and stiffness matrices were calculated in ANSYS, along with the first 80 eigen-frequencies and their corresponding mode shapes. The number of modes considered in the calculation was high enough to take into account the dynamic responses of the rails up to $1200 \mathrm{~Hz}$. According to [34], this is the adequate frequency range for studying impact phenomena related to discontinuities in the track.

\subsubsection{Modelling in SIMPACK}

The data calculated in ANSYS was then imported into SIMPACK. Elastic bodies described the left and right rails. SIMPACK uses the modal superposition technique in order to calculate the deformation of elastic bodies. The structural damping of the rails was considered to be negligible and was not taken into account.

As has been mentioned earlier, the embedded blocks were modelled directly in SIMPACK by means of force elements. This allowed for the introduction of non-lineal stiffnesses for the elastic blocks and facilitated the variation of the block spacing. The distance between the force elements or, in other words, the block spacing, was set to $1.0 \mathrm{~m}$, corresponding to the real value.

As previously indicated, the broken rail was modelled by two independent rails. By separating these rails, a gap between the two rails was obtained, simulating the broken rail.

On the other hand, the relative position of the gap between two adjacent blocks was adjusted by appropriately positioning the force elements. Fig. 9 shows the configuration that was considered in the final simulation models, with the train coming in from the left. 


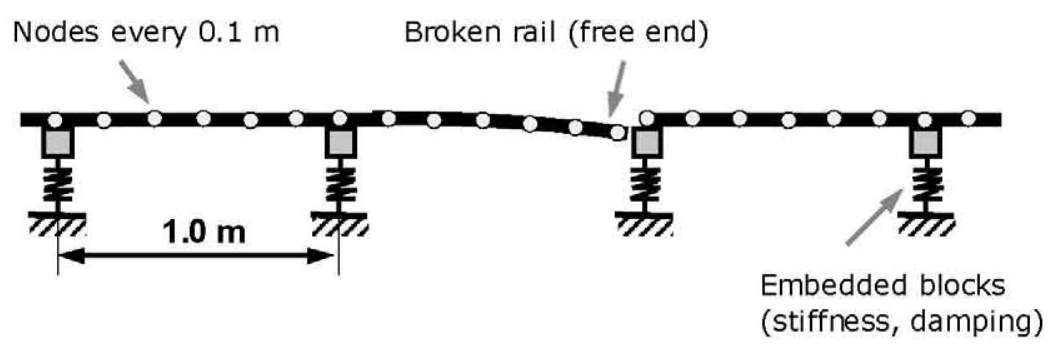

Fig. 9. Position of the gap that represents the broken rail

It can be seen that the train's wheels will run over a cantilever type stretch of the broken rail after passing over the last block that supports the rail before the gap. The cantilever section will deform under the train's weight and the wheels will face a collision with the rail that continues. As can be seen in the picture, by positioning the breakage just before the supporting block, the length of the cantilever rail reaches its maximum value of nearly $1.0 \mathrm{~m}$. Thus, the vertical deformation of the free end, caused by the train's weight, will also be greatest. This is considered the worst case scenario, since the collision of the wheel against the adjacent rail will have a greater impact.

The impact force depends highly on the degree of deformation of the cantilever rail. The deformation of the free end of the rail depends on the length of the free end, the embedded block system's properties, and, as will be shown later, also on the train's velocity.

\subsection{Description of the Combined Vehicle-Track Interaction Model}

The calculation of the wheel-rail interaction was realised by the MBS-simulation program's contact module. The contact condition between the wheel and the rail has been characterised by a Hertz contact spring with non lineal stiffness in the case of compression and zero stiffness in the case of traction (contact loss). The use of this spring allows for analysing situations in which the wheel looses contact with the rail, as is the case in derailment processes. The creepage forces are calculated by the program using the FASTSIM algorithm which applies a simplified Kalker theory.

Wheel-rail contact forces calculated by SIMPACK can only be directly applied on rigid bodies. Thus, in order to transfer wheel-rail normal forces to the elastic bodies used to model the rails, a set of auxiliary bodies had to be defined, as is described below.

First, a floating auxiliary body was defined per wheelset. Floating bodies rest on two vertical springs, and move also along the track, following one wheelset each. Loads from both wheels of each wheelset are transferred to the corresponding floating body through hertzian springs, which were automatically defined by the SIMPACK wheel-rail contact interface. After that, a set of moved markers were defined on each elastic body, in particular one marker per wheelset. As the floating bodies, each moved marker moves along its own elastic body, following a specific wheelset.

When no rails are broken, the left spring of the floating body was attached to a moved marker defined in the left rail, while the right spring was attached on a moved marker defined in the right rail (Fig. 10). The moved markers used to attach this springs were those which follow the same wheelset as the floating body. This way, the wheel normal force can be transferred through the vertical springs to the corresponding elastic bodies. 


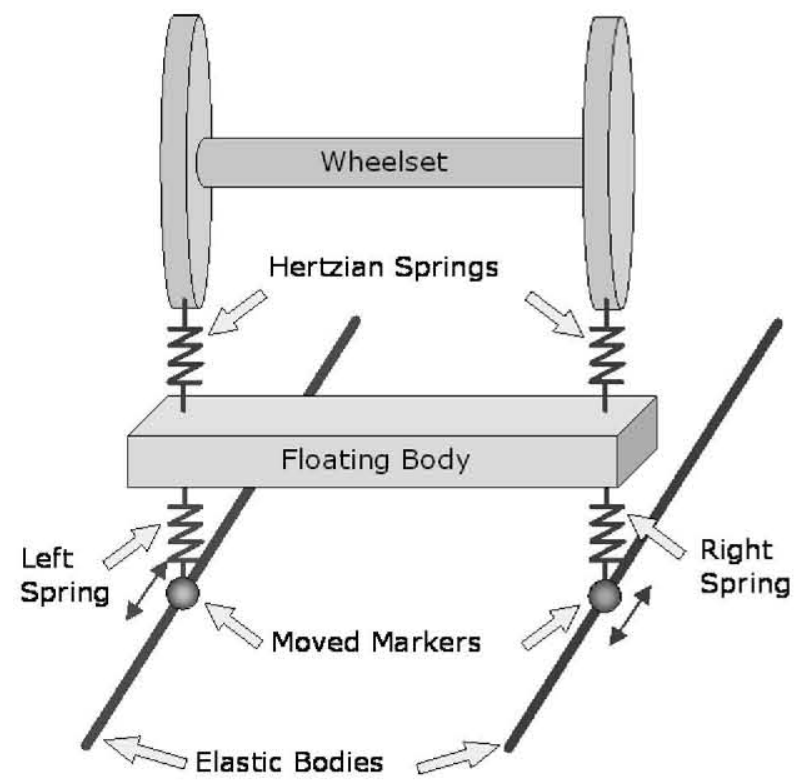

Fig. 10. Floating body and moved markers for standard elastic track

As the broken rail was modelled by two elastic bodies, a third vertical spring had to be added when the rail is broken, so that the floating body can be simultaneously connected with the three elastic bodies used to model the track (Fig. 11).

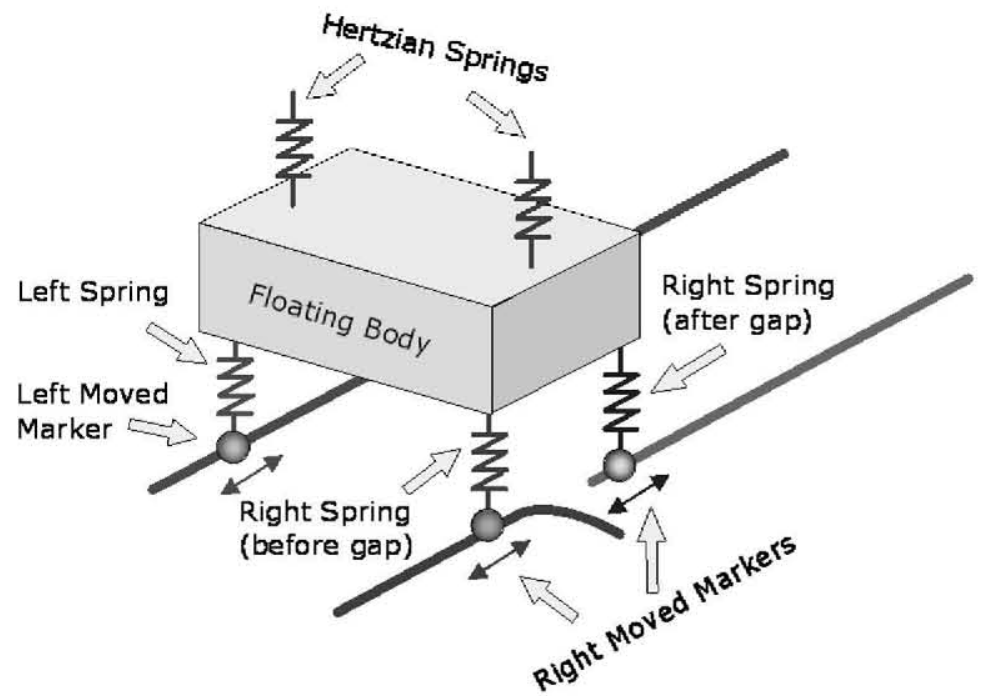

Fig. 11. Floating body and moved markers for models with a broken rail (right rail)

The presence of the broken rail added a further difficulty to the model, as the moved markers move along the track in a continuous way, not taking into account any discontinuity. To overcome this drawback, the wheel load had to be transfer only to that segment of the broken rail over which the wheelset is placed. Load transfer to the other segment should be avoided. To achieve this result, a special force element had to be programmed (in form of a FORTRAN user routine) for allowing the passing of the wheels from the rail before the gap to the rail after the gap. This force element provides a zero value when the wheelset is not directly placed over the elastic body on which the spring is fixed, being the force expression:

$$
F^{i}=\left\{\begin{array}{c}
k_{z} \cdot \Delta z+c_{z} \cdot v_{z}, \text { if }\left(x_{0}^{i}<x<x_{\text {end }}^{i}\right) \\
0 \text { otherwise }
\end{array}\right.
$$


where $i$ is the index of the aforementioned elastic body, and $x_{0}^{i}$ and $x_{\text {end }}^{i}$ are, respectively, its first and last node longitudinal coordinates.

In practice, when the wheel passes over the gap, it is simultaneously supported for a short time on the rails placed before and after the gap, transferring a part of its load to both rails. In order to reproduce this phenomenon in the model, the ends of both elastic bodies can be overlapped. Inside the overlapped length, the wheel has contact points at the same time with both elastic bodies, so allowing a multiple contact. This modelling technique has the advantage of allowing a progressive load transition from the rail before the gap to the rail after the gap. However, the overlapped length should be properly adjusted. As a drawback, although this length should be small (no more than a few centimetres), the cantilever section of the rail before the gap is slightly modified, at the same time that along the overlapped length the rail has double inertial properties. Some preliminary models were constructed in order to choose the most suitable length for the overlapped section. Finally, a zero overlapped length was chosen, being this the model for which the broken rail vertical displacements fit better to the experimental measurements described in the next paragraph.

Fig. 12 shows a snapshot of the final SIMPACK model used in the simulations. The deformation of the elastic track under the vehicle's weight has been represented after applying a scaling factor.

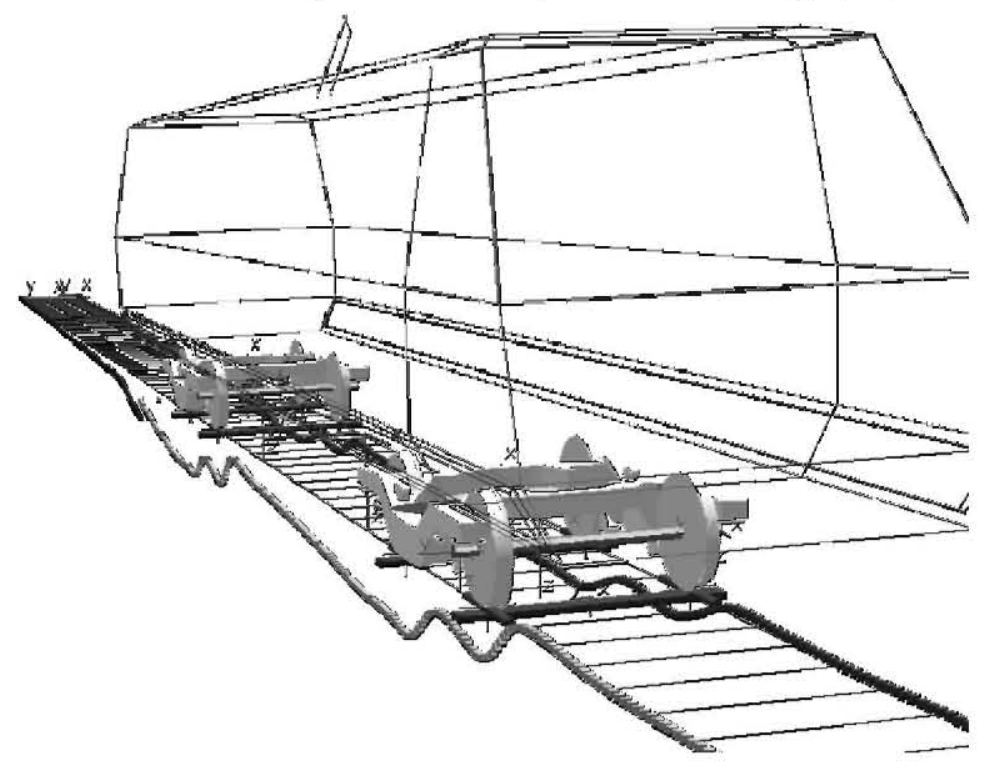

Fig. 12. The final MBS-model.

\section{$4 \quad$ Field Testing}

In order to verify that the free end of the simulated broken rail deformed to the same extent as in reality, some field testing was carried out on a $200-\mathrm{m}$-long, outdoor ballast track located in a maintenance depot. At first, measurements were realised with the rail still intact. Later, a gap was cut at half-distance between the two sleepers in order to obtain the broken rail.

Fig. 13 illustrates a sketch of the sensor set-up used for the field testing. 


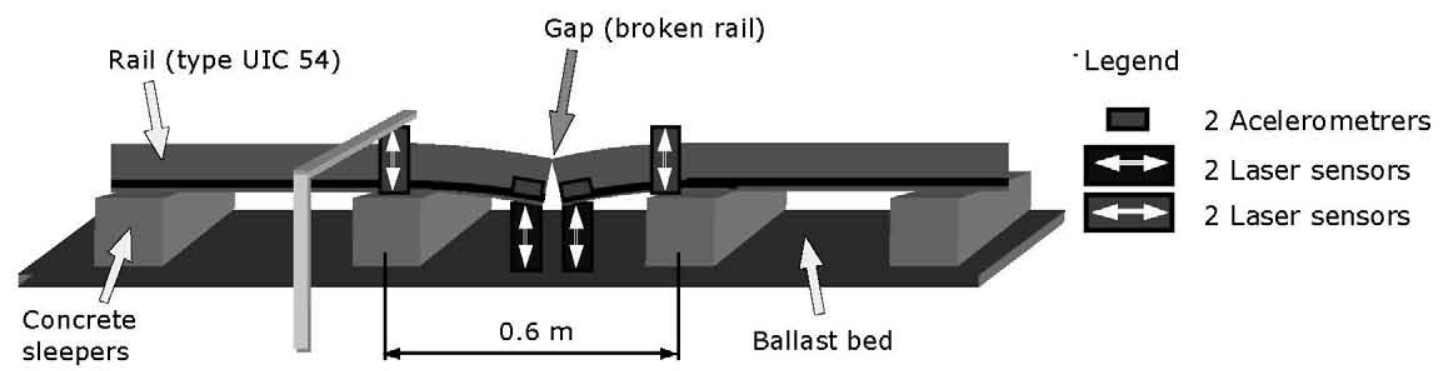

Fig. 13. Sensor positioning on the track at the measuring site

Two displacement sensors, based on laser technology, were installed track-side in order to measure the displacement of the two sleepers closest to the gap. Another two laser sensors were located in such a way that the deformation of the central part of the rail, which would later coincide with the free ends of the cut rail, could be recorded. Two accelerometers were also installed underneath free ends of the broken rail in order to complete the data acquisition.

Fig. 14 demonstrates photographs of the field testing spot and the measuring equipment.
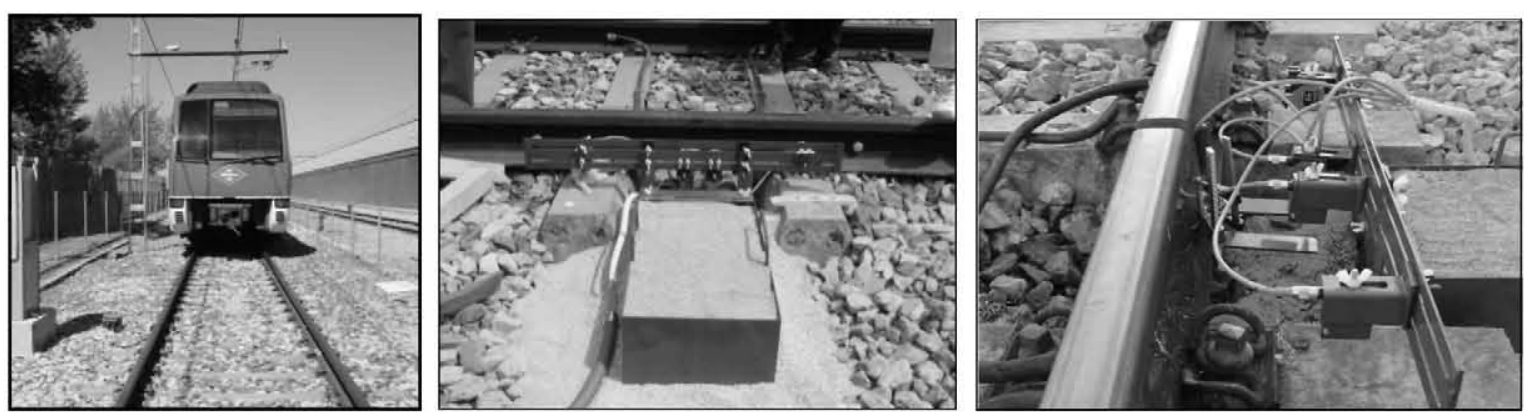

Fig. 14. The measuring equipment installed on the field testing site

As can be seen, the field testing was carried out on a ballast track with concrete sleepers, spaced equally every $0.6 \mathrm{~m}$. The simulation model was adapted to these requirements, in order to make the simulation and field testing results comparable. Fig. 15 shows the deflection measured in the sleeper with a train of the 6000 series passing over the track at $5 \mathrm{~km} / \mathrm{h}$, and the rail still being intact and uncut. The passing of the two wheelsets of the first bogie over the sleeper can be clearly observed. Results obtained in field testing have been indicated by two fine lines, corresponding to two different test runs. Results obtained in simulation have been shown by a thick line.

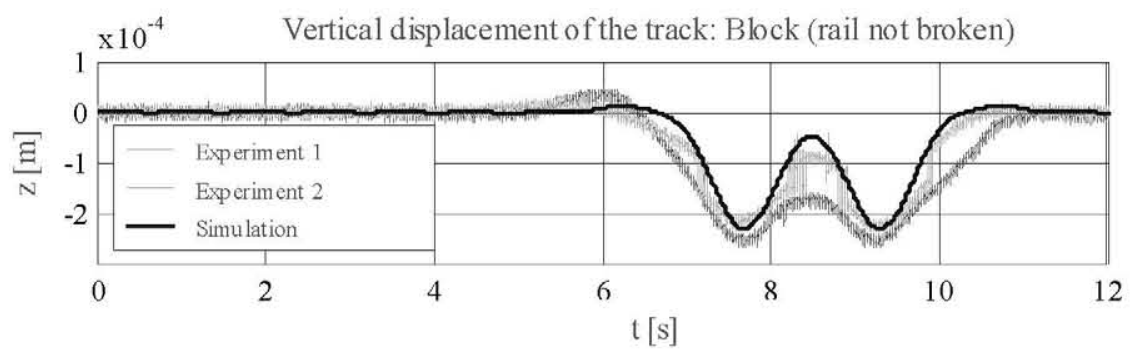

Fig. 15. Deflection of the sleepers with the train passing over it at $5 \mathrm{~km} / \mathrm{h}$

The measurements of the sleeper deflection with the rail still intact were used in the fitting of the stiffness values of the rail pad and the ballast. Once the model was adjusted, the rail was cut at halfdistance between the two sleepers and the measured deflection of the free ends was compared to the simulated values. The good agreement of the results obtained in field testing and simulation can be seen in Fig. 16, in which the experimental and simulated results have been indicated by thick and thin lines, respectively. 


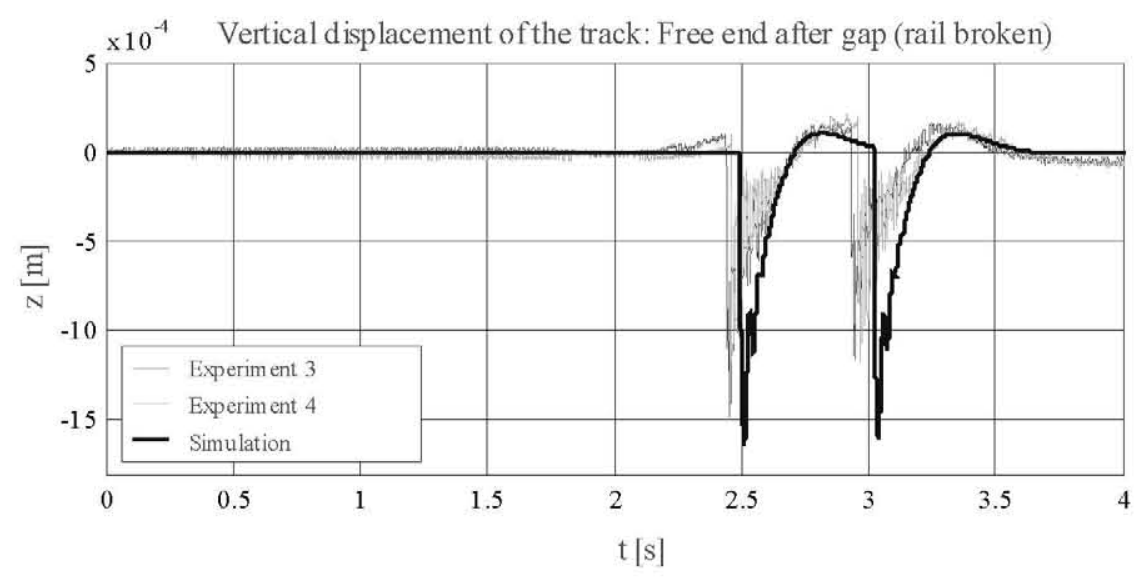

Fig. 16. Deflection of the second free end with the train passing over it at $15 \mathrm{~km} / \mathrm{h}$

Due to the good agreement obtained in measurement and simulation, it was decided to set up the broken rail model with the characteristics of the slab track described above.

\section{$5 \quad$ Simulations and Results}

The behaviour of the two, above-mentioned, types of embedded block systems were subjected to being studied in simulation. Specifically, the particular situation of a train encountering a broken rail was to be considered. It was also important to assess to what extent the train's stability and derailment safety would be affected by the broken rail, and whether or not a possibility for derailment existed.

\subsection{Assessment of the vehicle's running stability and derailment risk}

A vehicle's derailment risk can be estimated by evaluating the following two safety criteria:

- Derailment criterion (Nadal's criterion)

- Wheel unload criterion

Both criteria will be presented below. An explanation will be given as to why the latter was chosen for this study.

\subsubsection{Derailment criterion (Nadal's criterion)}

The best known safety criterion is the "derailment criterion", also known as "Nadal's criterion". This criterion evaluates the risk of flange climbing by establishing a relationship between the two most important forces involved in the flange climbing process: the lateral wheel force, $Y$, and the vertical wheel load, $Q$. These forces depend on the contact angle between flange and rail head, $\alpha$, the normal and frictional forces, $N$ and $T$, respectively, and the coefficient of friction, $\mu$. When the lateral wheel force overcomes the vertical downward force, the wheel flange might climb up the rail and consequently lead to a derailment due to flange climbing. As can be shown mathematically, the limit value for the derailment index, $Y / Q$, depends on the wheel profile's flange angle, $\alpha_{\text {flange }}$, as well as on the friction coefficient, $\mu$. The final formula reduces to:

$$
\frac{Y}{Q} \leq \frac{\operatorname{tg} \alpha_{\text {flange }}-\mu}{1+\mu \cdot \operatorname{tg} \alpha_{\text {flange }}}
$$

When applying the habitual values for $\alpha_{\text {flange }}=60$ to $70^{\circ}$, and $\mu=0.35$ to 0.40 , the limit value turns out to be: 


$$
\left(\frac{Y}{Q}\right)_{\lim }=0.8 \text { to } 1.2
$$

The experience acquired in various projects related to vehicle curving behaviour and, especially, research done on derailment reconstruction, led to the conclusion that usually the Nadal index suddenly approaches higher values just before a derailment occurs. Since the limit value is reached in a sudden and not progressive manner, this index is not very useful for evaluating the potential derailment risk. In other words, the train may have already reached a possibly dangerous situation while the Nadal index still gives save values far from the limit value. This is due to the fact that the Nadal criterion was developed for approximate quasi-static derailment calculation. Moreover, this index is not suitable for riding on straight track, as it evaluates the risk of flange climbing, which is most likely to occur when negotiating a curve.

\subsubsection{Wheel unload criterion}

Due to the cited limitations of Nadal's criterion, another typical safety criterion was analysed, the "wheel unload criterion". It had been noticed in previous studies, that this index shows a much clearer tendency than the Nadal index when a derailment situation is approached.

The wheel unload criterion evaluates the importance of wheel unloading when assessing the derailment risk. The criterion is derived from the force balance of a wheelset, when one wheel receives a higher (or lower) vertical load than the others (as is the case in curve negotiation). Again, the forces depend on the contact angle between flange and rail head, $\alpha_{L}$ and $\alpha_{R}$, for left and right-hand side, respectively, the total vertical and lateral forces acting on the wheelset, $W$ and $H$, and the coefficient of friction, $\mu$.

The final formula reduces to:

$$
\frac{\Delta Q}{Q_{0}}=\frac{\left(-\mu^{2} ; \operatorname{tg} \alpha_{L}-2 \cdot \mu+2 \cdot \phi \cdot\left(1+\mu \cdot \operatorname{tg} \alpha_{L}\right)\right.}{\left(+\mu^{2} ; \operatorname{tg} \alpha_{L}\right.}
$$

Where,

$\mu=$ coefficient of friction

$\alpha=$ contact angle between wheel and rail

$\phi=$ superelevation angle

The limit value for the wheel unload criterion, when applying the standard values of $\mu=0.36$, $\alpha=70^{\circ}$, and $\phi=0.1 \mathrm{rad}$, rounds up to:

$$
\left(\frac{\Delta Q}{Q_{0}}\right)_{\lim }=0.667
$$

The wheel unload criterion was found to be a much more stable and reliable indicator for assessing the derailment risk than Nadal's criterion. It was therefore the prime parameter analysed in the simulations.

\subsubsection{Other parameters considered in the vehicle-track interaction analysis}

To complete the evaluation of the vehicle's running behaviour, the vertical wheel load, $\mathrm{Q}$, was also calculated in the simulations.

The following, track-related quantities were also calculated:

- Vertical displacement and acceleration of the blocks closest to the broken rail

- Vertical displacement and acceleration of the free end of the broken rail 


\subsection{Simulations at the maximum running velocity}

As a first step, simulations were carried out for the maximum running velocity allowed on straight track:

$$
v=v_{\max }=105 \mathrm{~km} / \mathrm{h}
$$

Four simulations were carried out at the maximum running velocity, in which the two types of fastening systems (EBS-MS and EBS-LS) were combined with both the minimum and the maximum axle loads. The final four configurations, "A" to "D", are summarised in Table 2.

\begin{tabular}{|c|c|c|}
\hline$\#$ & $\begin{array}{c}\text { Embedded block system } \\
\text { (stiffness, damping) }\end{array}$ & $\begin{array}{c}\text { Axle } \\
\text { load }\end{array}$ \\
\hline $\mathrm{A}$ & \multirow{2}{*}{$k_{M S}, d_{M S}$} & $Q_{\min }$ \\
\cline { 3 - 3 } $\mathrm{B}$ & \multirow{2}{*}{$k_{L S}, d_{L S}$} & $Q_{\max }$ \\
\hline $\mathrm{C}$ & & $Q_{\min }$ \\
$\mathrm{D}$ & & $Q_{\max }$ \\
\hline
\end{tabular}

Table 2. The cases simulated

Fig. 17 shows a sequence of the MBS-simulation when passing over the broken rail. The deformation of the elastic rail has been multiplied by a scaling factor.
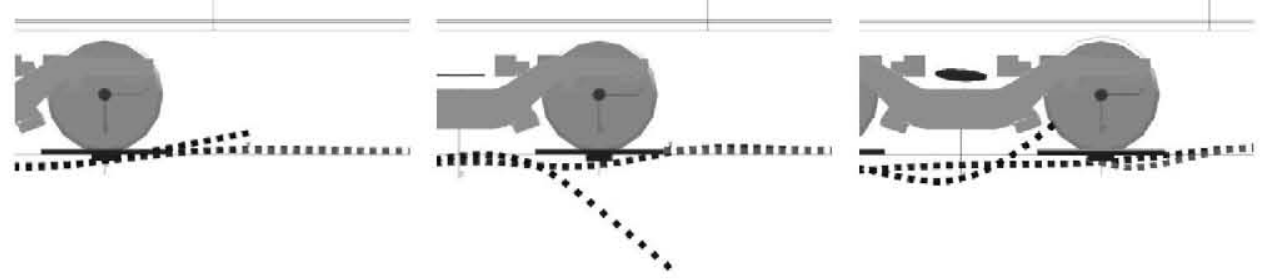

Fig. 17. Sequence of the MBS-simulation when passing over the broken rail

\subsubsection{Terminology used}

In order to make the interpretation of the graphs easier, the terminology shown in Fig. 18 has been used.

Bogie 1

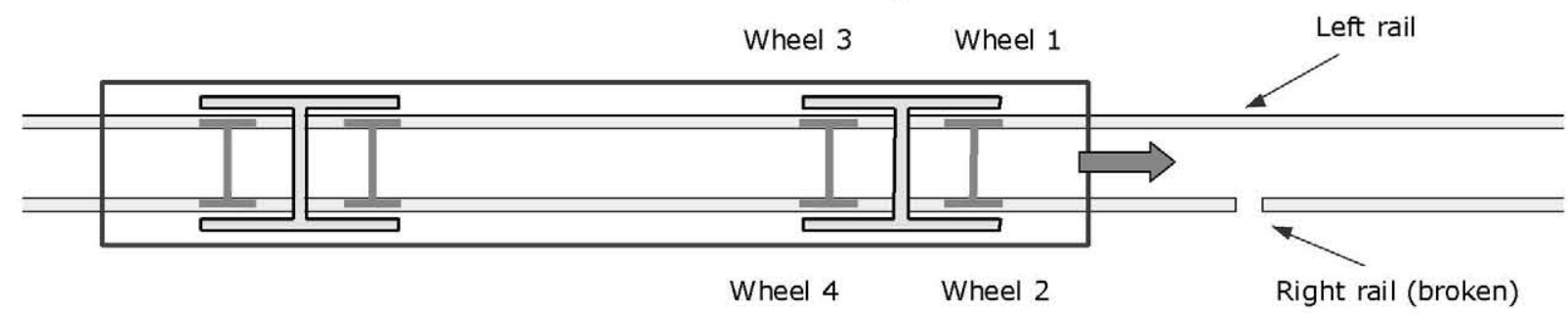

Fig. 18. Terminology used

\subsubsection{Results for case “ $A$ ”}

In this section some exemplary results for the case "A" configuration are presented. Fig. 19 shows the vertical deformation of the track at the last embedded block before the gap (upper figure) as well as the deformation of the free end of the cantilever rail (lower figure). The value for the static displacement $(v=0 \mathrm{~m} / \mathrm{s})$ has been represented by the discontinuous line. 

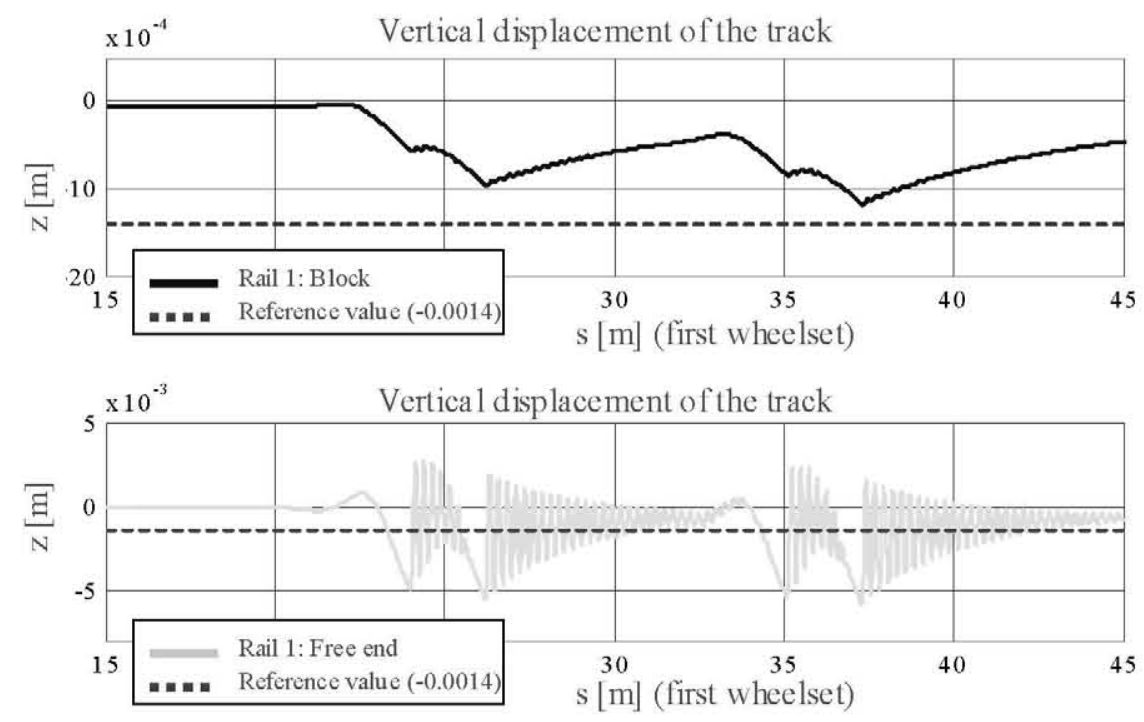

Fig. 19. Vertical displacement of the track (upper figure: last block before gap, lower figure: free end of the broken rail)

The passing of all four wheelsets over the embedded block and the free end can be easily observed. The first wheelset encounters the broken gap at the track position of $s=24 \mathrm{~m}$. Another interesting observation is that the last wheelsets reach a greater vertical displacement of the rail than the first ones. That is due to the fact that the damping properties of the slab track system do not allow the rail to recover its initial position in the short time period that exists between the passing of two successive wheelsets.

Fig. 20 includes the results of the vertical wheel load, $Q$, for the left and right wheels of the first wheelset when passing over the broken rail.

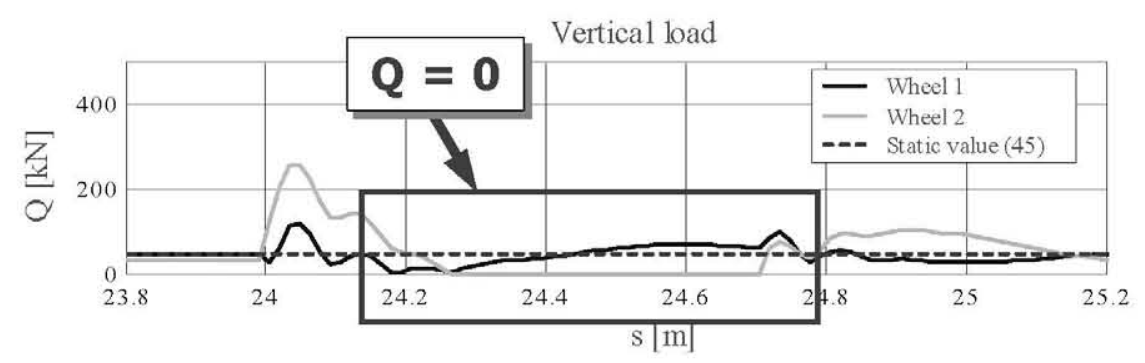

Fig. 20. Vertical load of the first wheelset

For about $0.6 \mathrm{~m}$ the vertical load of the right wheel (the broken rail was the right one) reaches zero, in other words, the wheel looses contact for $0.6 \mathrm{~m}$ which corresponds to 21 milliseconds when running at $105 \mathrm{~km} / \mathrm{h}$.

Fig. 21 shows the results for the wheel unload index. 


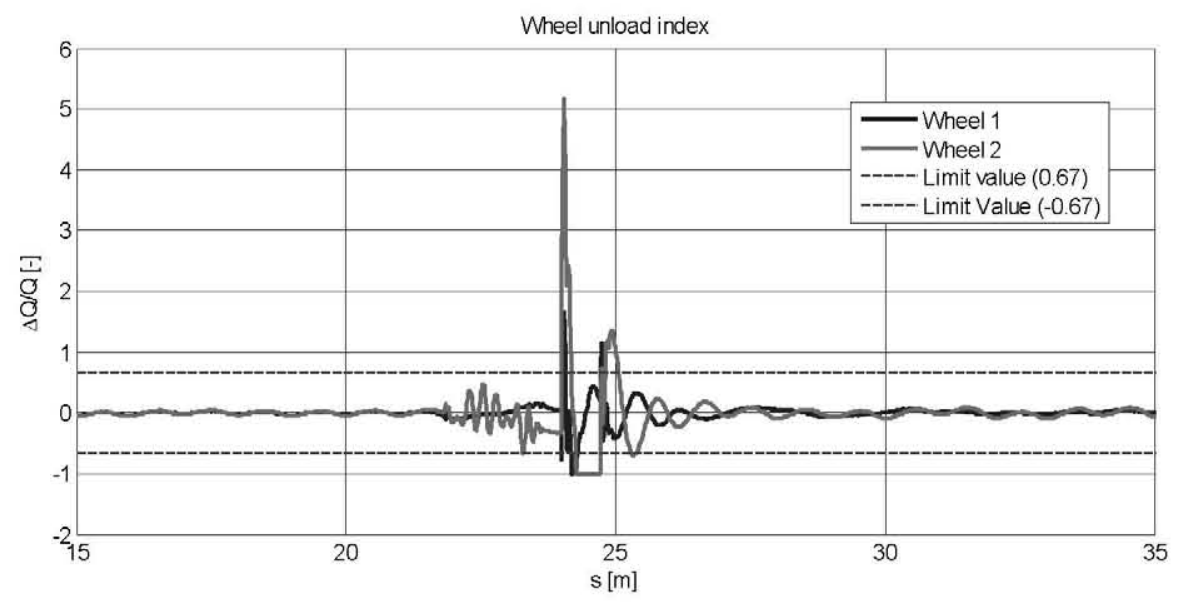

Fig. 21. Wheel unload index

It can be clearly seen that the limit value of 0.67 is surpassed instantaneously when the vehicle hits the extreme end of the broken rail $(\mathrm{s}=24 \mathrm{~m})$. However, as will be seen below, there is no derailment risk involved.

\subsubsection{Comparative results for cases " $A$ " to " $D$ "}

The vertical deflection of the free end and the wheel unload index will be shown in the following. Results in the space-domain have been calculated for all four cases, "A" to "D". However, in order to make the comparison of the results easier, only the maximum values were displayed and compared to each other.

The tendencies of the other parameters are similar, so that it was not considered necessary to present them all in this paper.

Vertical deflection of the free end

Fig. 22 shows the results of the maximum values for the vertical deflection of the free end of the broken rail of the four cases "A" to " $\mathrm{D}$ ".

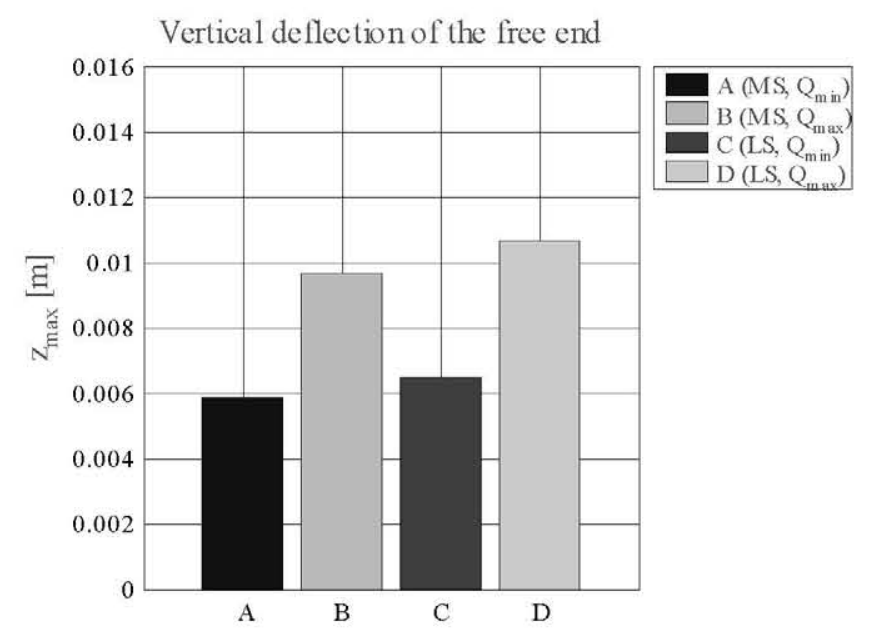

Fig. 22. Maximum vertical deflection of the free end

For each wheel load, it can be seen that the vertical deformation is almost the same for the two stiffnesses. Comparing the cases with the minimum weight, $Q_{\min }$, "A" and "C", systems MS and LS, respectively, it can be observed that there is almost no difference in the vertical deflection. The same tendency can be observed for the cases with the maximum load, $Q_{\max }$, whose deflections are higher due to the greater weight, but the difference between the MS and LS systems (cases "B" and "D", 
respectively) is negligible. This result is surprising at first, since greater elasticity usually leads to greater deflections. However, both the train's high running velocity and the slab track's damping characteristics do not permit the track to be deformed by the axle load as would happen with the train running at a very low speed or in a stationary position. This is due to the fact that at high running velocities the time available for the transfer of the wheel load to the rail is too short in order to deform it to its maximum possible value.

\section{Wheel unload criterion}

The maximum values for the wheel unload index for all four cases "A" to "D" are shown in Fig. 23 (on the left). In order to facilitate the direct comparison between the results of cases "A" to "D", the values obtained have been divided by the limit value. For this reason, the limit value indicated in the graphs by the reference line is equal to " 1 ".
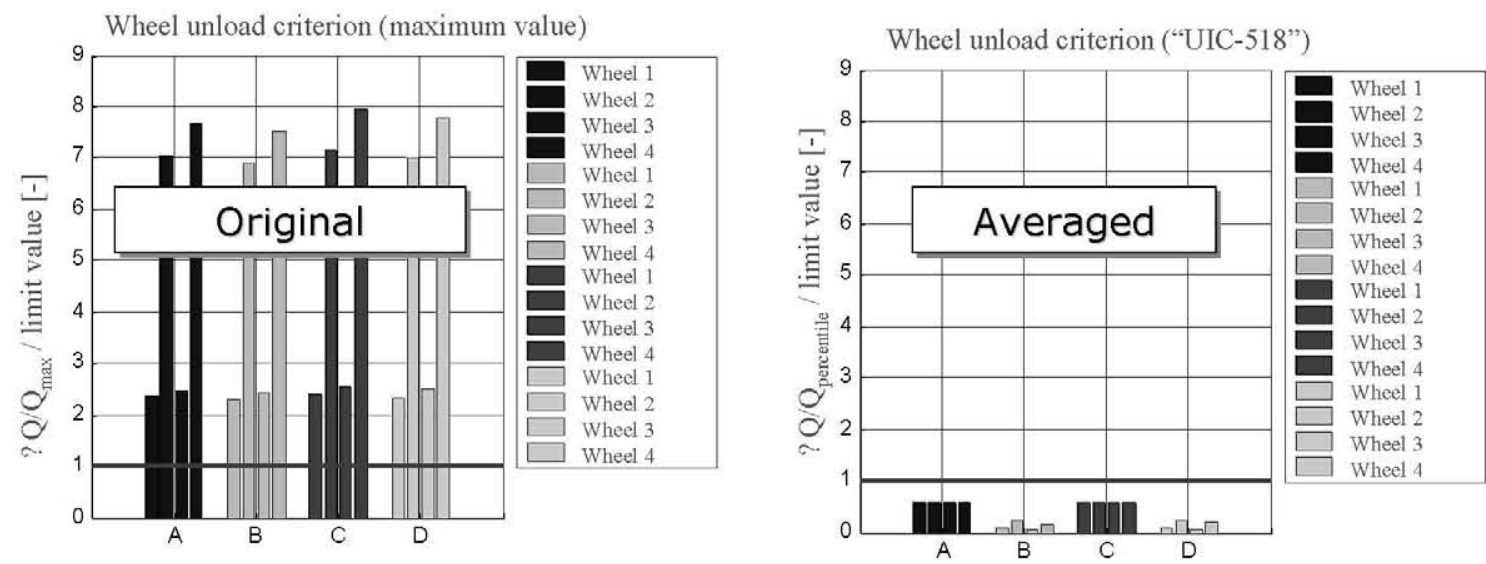

Fig. 23. Results for the wheel unload index (left: original instantaneous values, right: averaged values)

For all cases, "A" to "D", the wheels of the first bogie have been analysed. It can be clearly observed that in all cases the limit value is highly exceeded. Since the breakage is located on the right rail, wheels 2 and 4, located on the train's right-hand side (see Fig. 18 on the left), reach higher values. However, as has been indicated earlier, these maximum values are only reached during a very short interval of time that corresponds to the collision between the wheel and the broken rail. When assessing derailment risk using Nadal's index, Miyamoto [37] stated the importance of taking into account the time length during which this index is larger than its limit value. He suggested that the average value over time should be used as a new criterion for safety evaluation. Sharing this idea, Ishida et al. [38] suggested applying a $2 \mathrm{~m}$ window sliding mean, so ignoring instantaneously high values. This same value is recommended by the UIC-518 leaflet [39], were the $99.85 \%$ percentile is also used instead of the actual maximum value. Though no mention was found in the literature regarding statistical treatments for the wheel unload index, the authors considered to apply the same mathematical treatment to this index.

In Fig. 23 on the right it can be seen that all maximum values obtained after the treatment lie well below the limit value. These averaged results agree with the vehicle overall movements observed in the simulations, as no derailment occurs, despite the wheel lifts the rail along a short time.

\subsection{Simulations at lower running velocities}

Since for the high running velocity of $105 \mathrm{~km} / \mathrm{h}$, no significant difference had been observed in the results between the embedded MS and LS block systems, additional simulations at lower speed were carried out. 


\subsubsection{Comparative results for cases " $A$ " to " $D$ ": $v_{\max }$ and $v=0 \mathrm{~km} / \mathrm{h}$}

Fig. 24 shows the maximum values for the deflection of the free end of the broken rail for all cases "A" to "D". In the figure on the left, the results for the original configuration at $v_{\max }(105 \mathrm{~km} / \mathrm{h})$ are shown. On the right, the results with the train being stopped directly over the extreme end of the broken rail are included $(0 \mathrm{~km} / \mathrm{h})$.
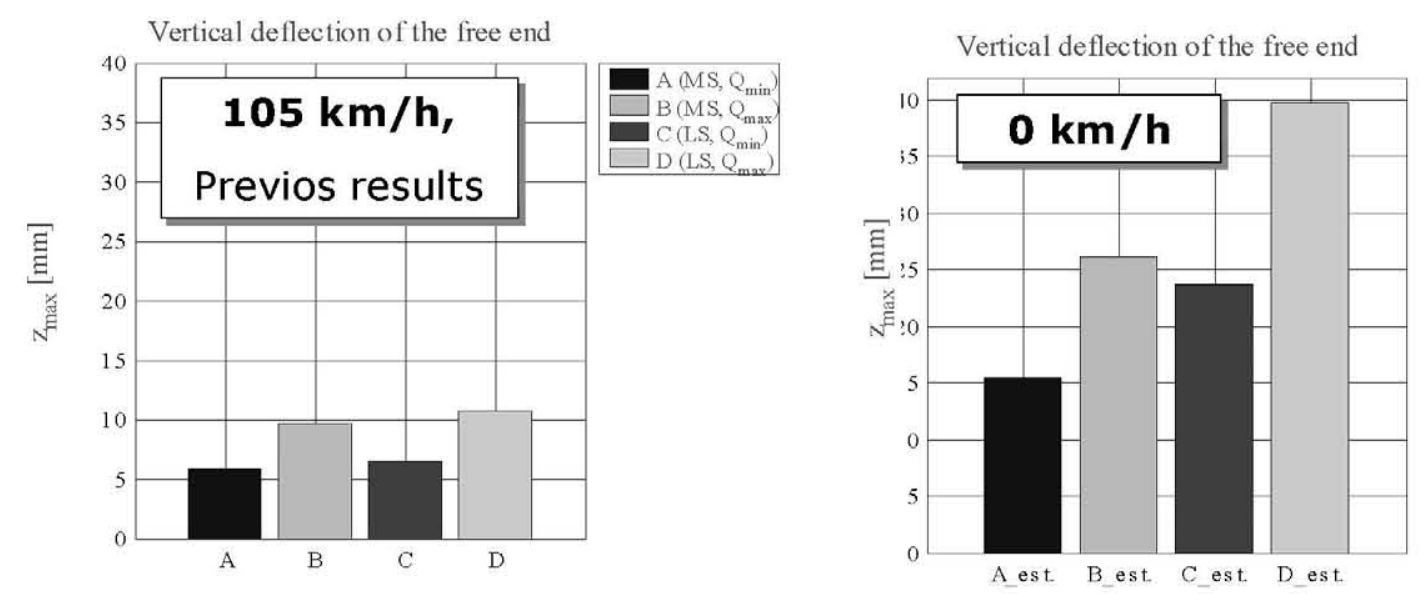

Fig. 24. Vertical deflection of the free end for $v_{\max }$ (left) and $v=0 \mathrm{~km} / \mathrm{h}$ (right)

For the high running velocity of $105 \mathrm{~km} / \mathrm{h}$, a negligible difference between the two MS and LS slab track systems had been observed (Fig. 24 on the left). Under static conditions, when the train rests on the free end of the broken rail (Fig. 24 on the right), the calculated maximum deflections are a lot higher, reaching maximum values of up to $40 \mathrm{~mm}$ for case " $\mathrm{D}$ ". This time, a clear difference for the calculated vertical maximum deformation can be observed when comparing the minimum to maximum axle loads: cases "A" and "C" (MS system) for $Q_{\min }$ and $Q_{\max }$, respectively, and cases "B" and "D" (LS system) for $Q_{\min }$ and $Q_{\max }$, respectively.

It should be noted that the values calculated under static conditions $(0 \mathrm{~km} / \mathrm{h})$ would probably be lower if the geometric characteristics of the embedded block had been taken into account in the model. In reality, the embedded blocks would present a non lineal stiffness. However, if the real characteristics had been considered, the results would have been less critical (lower values). Therefore it is assumed that the simulated results lie on the safe side.

\subsubsection{Results for case "D": Varying $v$}

For the case " $\mathrm{D}$ ", which had given the worst results, the influence of the running velocity on the vertical deflection of the free end is shown in Fig. 25. 


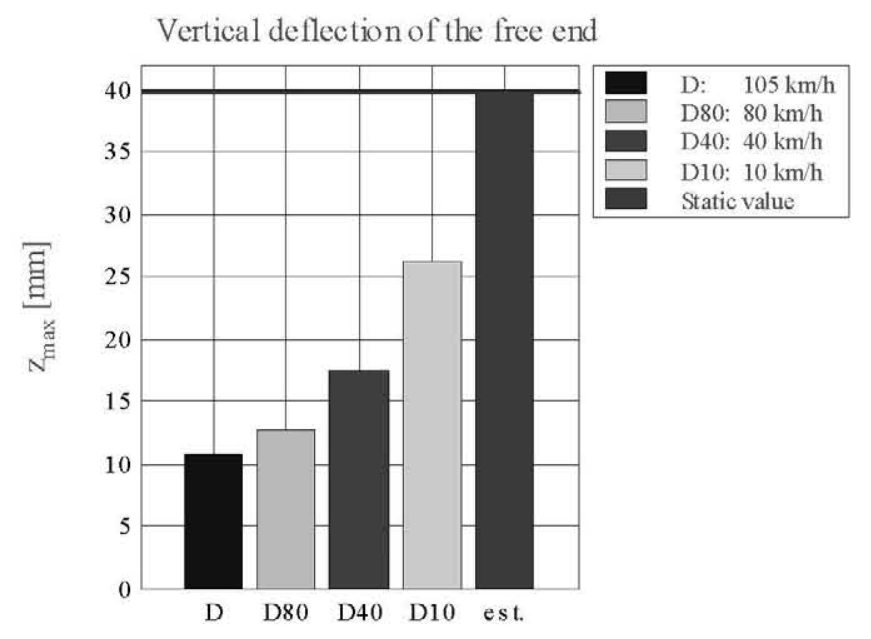

Fig. 25. Vertical deflection of the free end, when varying the velocity

It can be seen that the deflection grows as the train's velocity decreases.

The same tendency may be observed for the wheel unload index, lower velocities lead to higher maximum values (see Fig. 26).
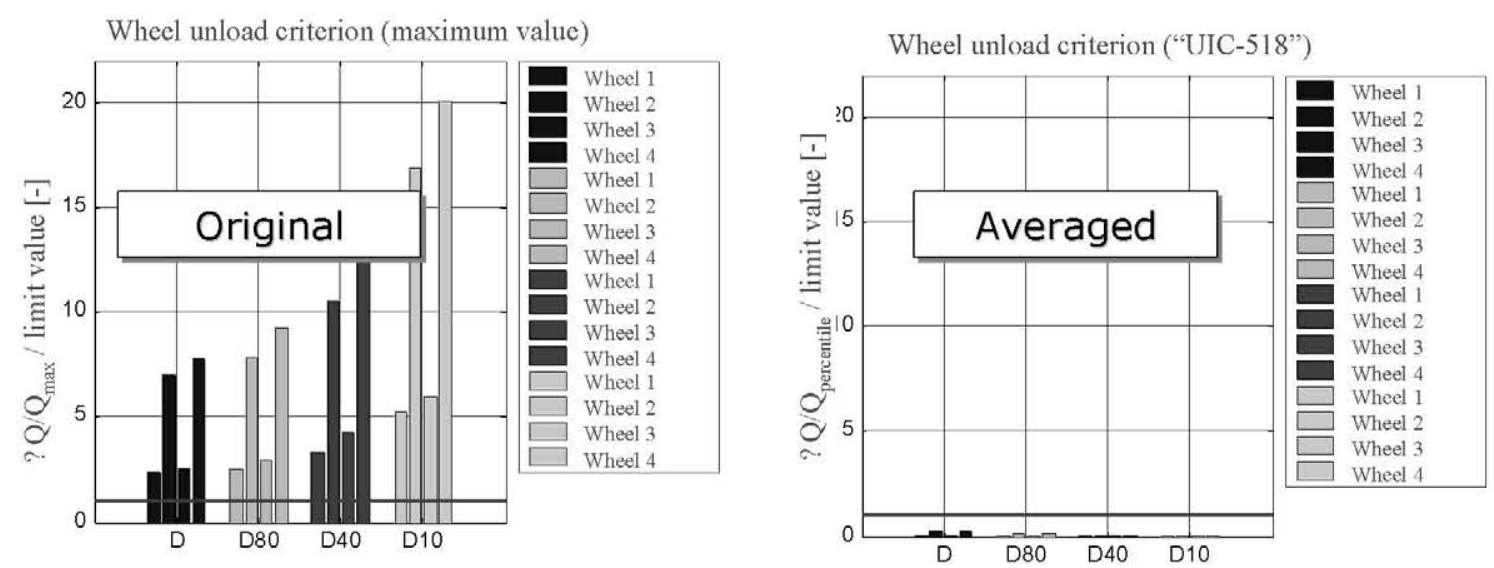

Fig. 26. Wheel unload index, when varying the velocity (left: instantaneous values, right: averaged values)

The lower the velocity, the higher the deflection of the free end and the greater the collision of the wheel against the broken rail. Nevertheless, when applying the already mentioned $2 \mathrm{~m}$ window sliding mean, all values end up much below the limit value and no derailment risk is to be expected. Again, it can be observed that the wheels that run over the broken rail (wheels 2 and 4) result in higher values.

\section{Conclusions}

In this study the influence of the passing over a broken rail on the train's overall dynamic behaviour and safety has been analysed for straight tracks. All simulations have been carried out for two different types of embedded block systems: LS, a low stiffness and, MS, a medium stiffness system. Simulations have been realised both at the highest running velocity and at lower speeds.

\subsection{Highest running velocity, $v_{\max }$}

In none of the simulations carried out at the highest running velocity, did a derailment occur.

Nevertheless, it was observed that the principal parameter used for assessing the derailment risk, the wheel unload index, $\Delta Q / Q$, instantaneously exceeded the limit value for the given velocity. However, after applying an habitual $2 \mathrm{~m}$ window sliding mean, the peak values fell well below the 
established limit value. Also, $Q_{\max }$ was found to be the critical axle load, since all parameters related to running stability and derailment risk had worse values. And last but not least, no significant difference in the results was noticed when comparing the two slab track systems, MS and LS.

\subsection{Lower running velocities}

In none of the simulations carried out at lower velocities than $v_{\max }$, did a derailment occur.

In a static analysis it was demonstrated that the system with the lower stiffness, LS, led to greater static deflections than the system with the medium stiffness, MS. However, when the running velocity was increased, the vertical deflections decreased and so did the difference between the two systems, LS and MS, which had been observed in the static case. Also, it was noticed that the wheel unload index was worse for lower running velocities, but when applying the sliding mean, all values lay beneath the limit values.

Last but not least, it can be concluded that, even though the behaviour on straight track is worse for lower running velocities, in none of the simulations has a dangerous situation been reached.

\subsection{Recommendations and outlook}

The following concepts have not been included in the present model and give way to future developments:

- Plastic deformation of the free end of the broken rail

- Track irregularities

- Incorporation of a contact model simulating the frontal collision between wheels and broken rail

- Non lineal vertical stiffness of the embedded block system

- Train compositions of more than one wagon

Currently, appropriate simulation models for analysing the influence of a broken rail in curves are being developed.

\section{ACKNOWLEDGEMENTS}

The authors gratefully acknowledge the kind help and advice of Manuel Vázquez, Alejandro Chércoles, and Gabriel Banzo (Metro de Madrid) during the preparation of this research project. Special thanks go to Pablo Rodríguez (CITEF) for his contributions made during the modelling process.

This work would not have been possible without the initiative of our Director Prof. Carlos Vera (CITEF), who introduced us to the principals of vehicle system dynamics and who could not experience the completion of this project due to his premature decease on November 21, 2005.

\section{REFERENCES}

[1] Polach, O., Berg, M. and Iwnicki, S.: "Simulation". In: Iwnicki, S. (ed), Handbook of railway vehicle dynamics. CRC Press, 2006. pp. 143-179. ISBN: 0849333210

[2] Dahlberg, T.: "Track Issues". In: Iwnicki, S. (ed), Handbook of railway vehicle dynamics. CRC Press, 2006. pp. 143-179. ISBN: 0849333210

[3] Esveld, C.: "Modern Railway Track". MRT-Productions, 2001. ISBN: 90-800324-3-3

[4] Afonso Ferreira, P., López-Pita, A., "Modelling Dynamic Behaviour of Very High-Speed Railways to Evaluate Track Vibration and Deterioration", Railway Engineering - 2005, London, UK, 29-30 June, 2005.

[5] Frýba, L., "History of Winkler Foundation". Vehicle System Dynamics Supplement, Vol. 24, pp. 7-12, 1995.

[6] Moravčík, M., "Response of Railway Track on Nonlinear Discrete Supports". Vehicle System Dynamics Supplement, Vol. 24, pp. 280-293, 1995. 
[7] Ahlbeck, D. R., "Effects of Track Dynamic Impedance on Vehicle-Track Interactions". Vehicle System Dynamics Supplement, Vol. 24, pp. 58-71, 1995.

[8] Thompson, D. J. and Vincent, N., "Track Dynamic Behaviour at High Frequencies. Part 1: Theoretical Models and Laboratory Measurements". Vehicle System Dynamics Supplement, Vol. 24, pp. 86-99, 1995.

[9] Jaschinski, A., "Multibody Simulation of Flexible Vehicles in Interaction with Flexible Guideways". Vehicle System Dynamics Supplement, Vol. 24, pp. 31-44, 1995.

[10] Knothe, K., Wu, Y. and Gross-Thebing, A., "Simple, Semi-Analytical for Discrete-Continuous Railway Track and their Use for Time-Domain Solutions". Vehicle System Dynamics Supplement, Vol. 24, pp. 340-352, 1995.

[11] Young, T. H. and Li, C. Y., "Vertical Vibration Analysis of Vehicle/Imperfect Track Systems". Vehicle System Dynamics, Vol. 40, pp.329-349, 2003.

[12] Ripke, B. and Knothe, K., "Simulation of High Frequency Vehicle-Track Interactions". Vehicle System Dynamics Supplement, Vol. 24, pp. 72-85, 1995.

[13] Dahlberg, T., "Vertical Dynamic Train/Track Interaction - Verifying a Theoretical Model by Full Scale Experiments". Vehicle System Dynamics Supplement, Vol. 24, pp. 45-57, 1995.

[14] Eisenmann, J.: "Die Schiene als Tragbalken (El Carril como Viga de Soporte)", EI Eisenbahningenieur (55), 5/2004, pp. 22-25.

[15] Zakeri, J. A., "Statistical Analysis of Rail Breakage and Rail Welding Failures in Iranian Railways", Railway Engineering - 2005, London, UK, 29-30 June, 2005.

[16] Zarembski, A. M., Palese, J. W., "Managing Risk on the Railway Infrastructure", Proceedings of the 7th World Congress on Railway Research, Montreal, June 4-8, 2006.

[17] Wu, T.X. and Thompson, D.J., "The Effects of Track Non-Linearity on Wheel/Rail Impact". Journal of Rail and Rapid Transit, Vol. 218, pp. 1-15, 2004.

[18] Jeong, D. J., "Engineering Study of Dynamic Loads at Rail Joints". 2001.

[19] Dukkipati, R. V. and Dong, R., "The Dynamic Effects of Conventional Freight Car Running over a Dipped-joint". Vehicle System Dynamics, Vol. 31, pp. 95-111, 1999.

[20] Andersson, C. and Dahlberg, T., "Wheel/Rail Impacts at a Railway Turnout Crossing". Journal of Rail and Rapid Transit, Vol. 212, pp. 123-134, 1998.

[21] Esveld, C. and Steenbergen, M., "Force-Based Assessment of Rail Welds". Proceedings of the 7th World Congress on Railway Research, Montreal, June 4-8, 2006.

[22] Vanhonacker, P. and Van Leuven, A., "Super Resilient Rail Fixation Systems to Reduce Squeal Noise, Vibration and Rail Corrugation", Railway Engineering - 2005, London, UK, 29-30 June, 2005.

[23] Bergoend, J. P., Petin, B. and Robertson, I., "Achieving S3 or the Development of a Highly Resilient High-Speed Slab Track for the Channel Tunnel Rail Link", Railway Engineering 2005, London, UK, 29-30 June, 2005.

[24] Thompson, D. and Jones, C.: "Noise and Vibration from Railway Vehicles". In: Iwnicki, S. (ed), Handbook of railway vehicle dynamics. CRC Press, 2006. pp. 279-325. ISBN: 0849333210

[25] Melis, M.: "Terraplenes y balasto en Alta Velocidad Ferroviaria (Primera parte)", Revista de Obras Públicas, Marzo 2006, N 3464, pp. 7-36

[26] Melis, M. and González, F.J.: "Ferrocarriles Metropolitanos. Tranvías, Metros Ligeros y Metros Convencionales", Colegio de Ingenieros de Caminos, Canales y Puertos, 2004. ISBN: 8438002870

[27] Melis, M. and Matías, I.: "Vía en Placa en la Ampliación del Metro de Madrid. Reducción de los Costes de Mantenimiento". Revista de Obras Públicas, No. 3375, Apr. 1998, pp 17-34

[28] Miura, S., Takai, H., Uchida, M. and Fukada Y.: "The Mechanism of Railway Tracks". In: Wako, K. (ed), Railway Technology Today 2, Japan Railway \& Transport Review, March 1998, pp. 3845

[29] Zoeteman, A. and Esveld, C., "Evaluating Track Structures: Life Cycle Cost Analysis as a Structured Approach", World Congress on Railway Research, Tokyo, October 1999.

[30] Man, A. and Hoogendoorn, C.: "Mechanical Test Results EBS Low Stiffness - Metro de Madrid", EDILON Report R4293, January 2005 
[31] Houwen, G. and Wiltink, F.: "Mechanical Properties of the Metro de Madrid Medium Stiffness Embedded Block System", EDILON Report R3713, March 2002

[32] Edilon Rail Systems [on line]. "Edilon Corkelast $\mathbb{R}$ Embedded Block system" [cited 19 November 2006]. Available from: $<$ http://www.edilon.com $>$.

[33] Ingenieria de Vias Elasticas [on line]. Sistema Bibloque sin Riostra [cited 19 November 2006]. Available from: $<$ http://www.viaselasticas.com $>$

[34] Knothe, K. and Grassie, S.L.: "Modelling of Railway Track and Vehicle/Track Interaction at High Frequencies", Vehicle System Dynamics, Vol. 22, 1993, pp. 209-262

[35] Schupp, G., Weidemann, C and Mauer, L.: "Modelling the Contact Between Wheel and Rail Within Multibody System Simulation". Vehicle System Dynamics, Vol. 41, pp.349-364, 2004

[36] Gonzalez F.J., Blanquer, J.F., Suarez, B. and Rodriguez, P.: "Models of Metro de Madrid Rolling Stock and Comparative Studies Relating the Comfort", 6th International Conference on Railway Bogies and Running Gears, Budapest, Hungary, 13-16 September, 2004

[37] Miyamoto, M.: "Mechanism of Derailment Phenomena of Railway Vehicles", QR of RTRI, Vol. 37, 1996, pp. 147-155.

[38] Ishida, H. and Matsuo, M.: "Safety Criteria for Evaluation of Railway Vehicle Derailment", QR of RTRI, Vol. 40, 1999, pp. 18-25.

[39] UIC 518: "Testing and approval of railway vehicles from the point of view of their dynamic behaviour - Safety - Track fatigue - Ride quality", Union Internationale des Chemins de Fer (UIC), 2005

\section{APPENDIX}

\section{Notation}

$\begin{array}{ll}R B I & \text { Rail Breakage Index } \\ d & \text { Embedded block vertical damping } \\ d_{L S} & \text { EBS-LS vertical damping } \\ d_{M S} & \text { EBS-MS vertical damping } \\ k & \text { Embedded block vertical stiffness } \\ k_{L S} & \text { EBS-LS vertical stiffness } \\ k_{M S} & \text { EBS-MS vertical stiffness } \\ l & \text { Block spacing } \\ v & \text { Train running velocity } \\ v_{\max } & \text { Train maximum running velocity } \\ s & \text { Longitudinal track position } \\ & \\ H & \text { Lateral force acting on the wheelset } \\ N & \text { Normal wheel force } \\ T & \text { Friction wheel force } \\ Y & \text { Lateral wheel force } \\ Y / Q & \text { Derailment index (Nadal's index) } \\ (Y / Q)_{l i m} & \text { Nadal criterion } \\ Q & \text { Vertical wheel load } \\ Q_{\min } & \text { Minimum axle load } \\ Q_{\max } & \text { Maximum axle load } \\ W & \text { Vertical force acting on the wheelset }\end{array}$


$\alpha$

$\alpha_{\text {flange }}$

$\alpha_{L}$

$\alpha_{R}$

$\phi$

$\mu$

$\triangle Q / Q$

$\left(\triangle Q / Q_{0}\right)_{\text {lim }}$
Contact angle between wheel and rail

Wheel profile's flange angle

Contact angle between left flange and rail head

Contact angle between right flange and rail head

Superelevation angle

Coefficient of friction

Wheel unload index

Wheel unload criterion 